\title{
INTERIOR LIGHTING OF A HISTORICAL BUILDING BY USING LED LUMINAIRES: A CASE STUDY OF FATIH PAŞA MOSQUE
}

\author{
Serhat Berat Efe ${ }^{1}$ and Derman Varhan ${ }^{2}$ \\ ${ }^{1}$ Department of Electrical Engineering, Bandırma Onyedi Eylül University, Turkey \\ ${ }^{2}$ General Directorate of Foundations, Provincial Directorate of Diyarbakır, Turkey \\ E-mail: sefe@bandirma.edu.tr
}

\begin{abstract}
In this study, a place of worship lighting in accordance with CIE standards was examined. Halogen lamps were used in the place of worship lighting, which was physically applied. Halogen lamp lighting and LED illuminated place of worship environment were compared in terms of luminance level and economic cost in a simulation environment. The illumination level should be $100 \mathrm{~lx}$ or above for places of worship according to CIE standards. Lighting using LED lamps, which provide $100 \mathrm{~lx}$ illuminance levels, has yielded $85 \%$ more efficient results than illumination by halogen lamps.

Keywords: energy efficiency, LED, historical place, artificial lighting, illuminance, energy consumption

\section{INTRODUCTION}

Illuminance, which is physically defined as the luminous flux at the unit area, is also expressed as the perceptibility level of the environment or as a result of the light's usability. There are two types of lighting: day lighting and artificial lighting [1-2].

The lighting pattern of natural light differs hourly, seasonally, and would change according to weather conditions. Since it is not possible to provide illumination at any time with daylight, artificial lighting is preferred in the lighting of the places where the lighting needs are obvious [3-5]. Good and accurate lighting increases work efficien-
\end{abstract}

cy and economic development, prevents accidents, prevents eye distortion, improves eye perception, and improves living comfort. The structure of the place to be illuminated and the reason for the illumination necessity determines the criteria of the lighting installation.

The characteristics of the area to be illuminated affect the criteria for determining the lighting element to be selected as the aesthetic quality of the architectural building. These characteristics should be considered in terms of comfort-related concepts such as glare, colour rendering index, and correlated colour temperature of the light sources used [6-8].

This study focuses on the lighting of a historical mosque located in Diyarbakır, Turkey. The topic was chosen because much too little study has been done on both lighting and modernization of illumination systems for historical buildings [9]. Within the scope of the study, principals about to lighting design of the historical buildings and the advantages of using LED lighting at such places are investigated in terms of energy savings. In the proposed study, modern and low energy consumption LED luminaires have been adapted instead of inefficient lighting elements in the historical building. In this way, while achieving illuminance levels in accordance with the standard, energy savings were achieved at the same time. During the design and assembly stages of the lighting elements, the originality of the building was fully protected.

A lighting project implemented in this study was analysed according to the International Lighting 

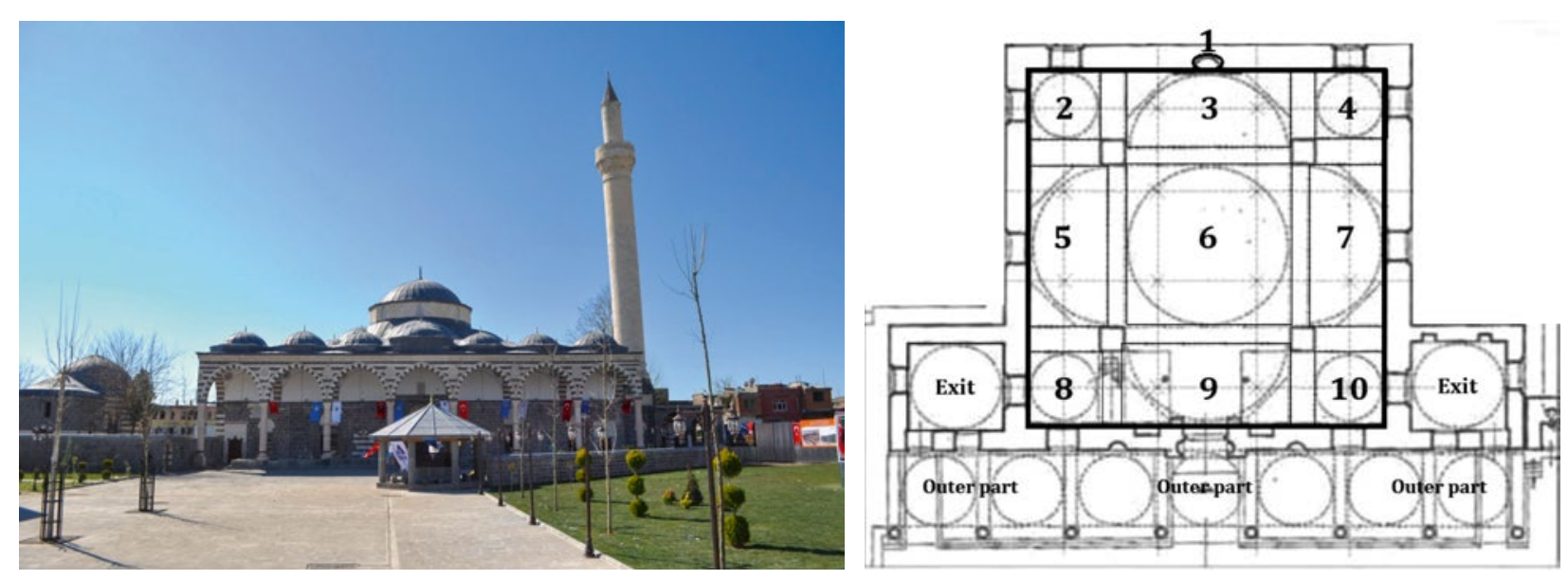

Fig. 1. Practiced place of worship and numbered lighting areas [28, 29]

Commission (CIE) standard [13]. For this purpose the lighting application in the project was compared by a non-commercial simulation program.

\section{LED LIGHTING}

Energy consumption for lighting increases day by day. Due to the unconscious use of energy resources, the lack of sufficient technical infrastructure to reach renewable energy sources, and the high-energy amounts, the importance of saving in lighting has increased remarkably [10-12].

In order to provide efficiency in protecting the health and comfort of users, it was established that fluorescent bulbs, which are used instead of incandescent lamps in new projects, have lost their effectiveness and LED lamps are preferred as much as possible. Light emitting diodes (LEDs), the latest technology used in artificial lighting, are regarded as the most important invention in the history of lighting after the electric lamp that Edison discovered centuries ago $[14,16]$.

Lighting elements with high efficiency and colour diversity have been obtained in lighting by developments in semiconductor technology. LEDs are also the product of this development. For example, instead of a $60 \mathrm{~W}$ incandescent filament lamp, 9W LED array can be used to save (80-85)\% energy [17-22]. Because LEDs are used both as a single light source and as a fixture, the LEDs that enable the improvement of energy efficiency in lighting need to be evaluated differently than traditional light sources. For example, LED lamps can be used for all kinds of software and communication [23-26].

\section{A PLACE OF WORSHIP LIGHTING WORK}

Exhibition of the historical places in a proper and decent way has gained importance and in the last few years, many new and different methods have been used on it. Proper illumination is the best way to figure out these properties. The main goal of lighting is to provide excellent vision with low energy consumption. In addition, it is vital not to harm the historical buildings and their prominent features. In this paper, the illumination of a historical building has been discussed. An ancient mosque was selected as a status study. First, considering the indoor illumination level criteria identified by standards and using original architectural plans, the areas to be illuminated in this historical building were determined. Then, the designated areas were illuminated without damaging the historical place and giving importance to visualisation. Proposed systems were implemented experimentally to determine the most accurate results by the addition of environmental and architectural effects. One-year energy consumption comparison of two type lighting methods was proposed by using energy tariff data.

In general, the main objectives of the illumination design of a historical building should be:

- The main architectural elements, ornaments, valuable elements of the registered cultural heritage should be compatible with the original texture in a way that emphasizes the social and historical importance as well as the value of the moment and document along with the original pieces of that work;

- Make it possible to observe and perceive the area in a qualified way; 


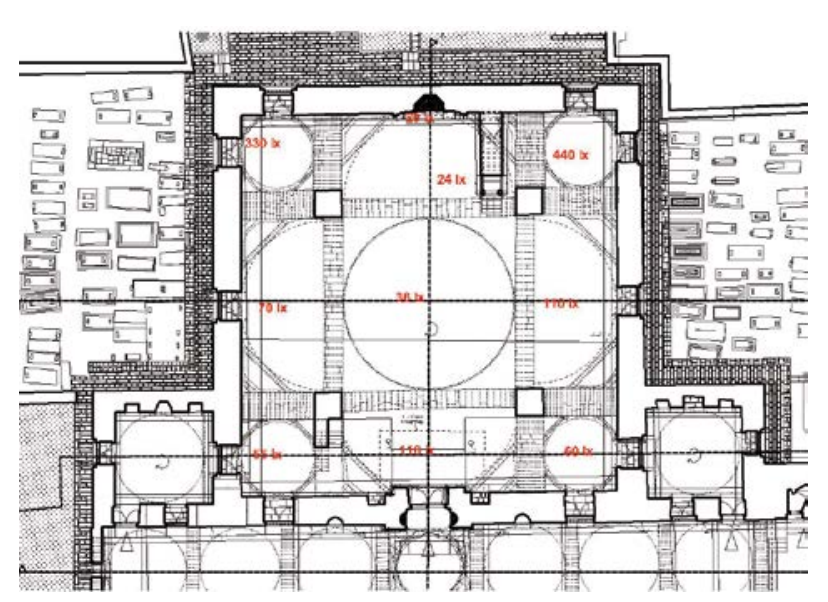

Fig. 2. Indoor daylight luminance levels measurement values

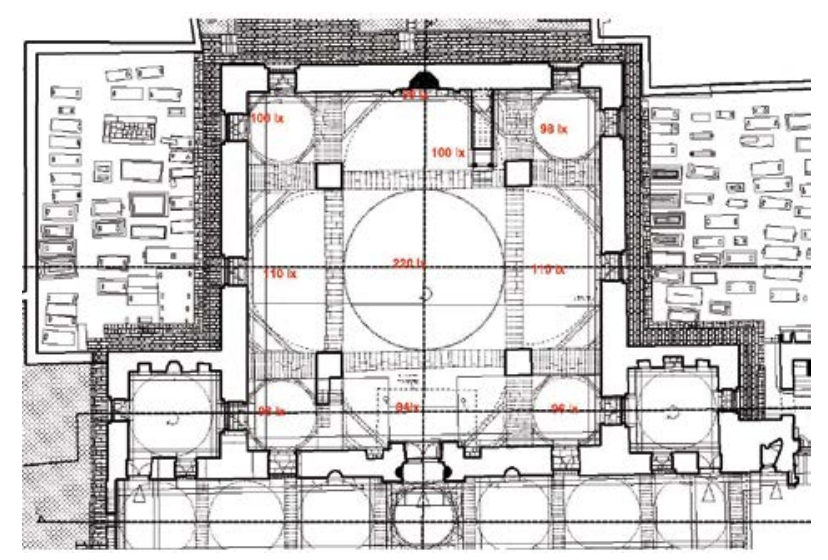

Fig. 4. Experimental measurement of indoor illuminance levels when using lighting elements at night

- To support the safety of works, especially in the old districts of cities, to increase user living, sightseeing and roaming comfort at night;

- To develop an approach that is appropriate to the principles of restoration besides aesthetics;

- Minimizing environmental impacts and maximizing energy savings while reaching desired illuminance levels [27].

Illumination of Fatih Paşa Mosque that built in Diyarbakır between 1516 and 1520 selected as a case study was performed according to these objectives. The place of worship and numbered lighting areas are shown in Fig. 1.

There are both indoor and outdoor illumination applications in this study. While the outdoor illumination is only for visualisation, this study focused on indoor illumination that has to meet standards. The minimum indoor illuminance level for worship is determined as $100 \mathrm{~lx}$ according to the CIE standard [13].

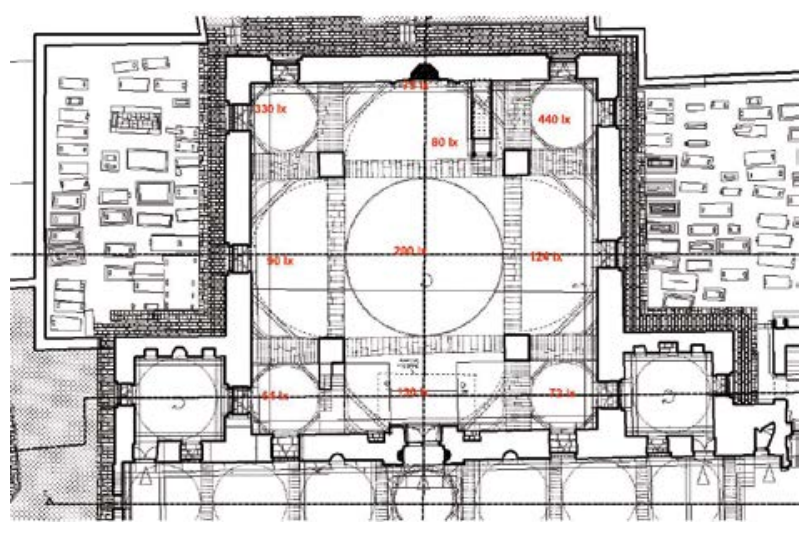

Fig. 3. Indoor experimental illuminance measurements with only the central luminaire open during daytime

In the Fatihpaşa Mosque, during the daylight hours, the illuminance levels were measured without lighting elements as shown in Fig. 2. It is seen that the illuminance levels are very high in some areas with daylight only and it is well below the desired in some areas.

Fig. 3 shows the measurements made using only the central lighting chandelier. It was observed that only the central chandelier was used during the day to provide the appropriate illumination levels for the place of worship. Fig. 4 shows measurements made using only lighting installations in the night. Indoor view of mosque after installation completed is given in Fig. 5. Table 1 shows the illuminance values according to the places of worship in manual measurements.

The lamps that operate actively during the day or at night are the lamps in Area-6. When Table 1 is examined, in the measurements made physically, $36 \mathrm{~lx}$ for $5 \mathrm{~m}$ height was measured in daylight in Area-6. During the day, when artificial lighting is made only in Area-6, 200 lx was measured. Again,

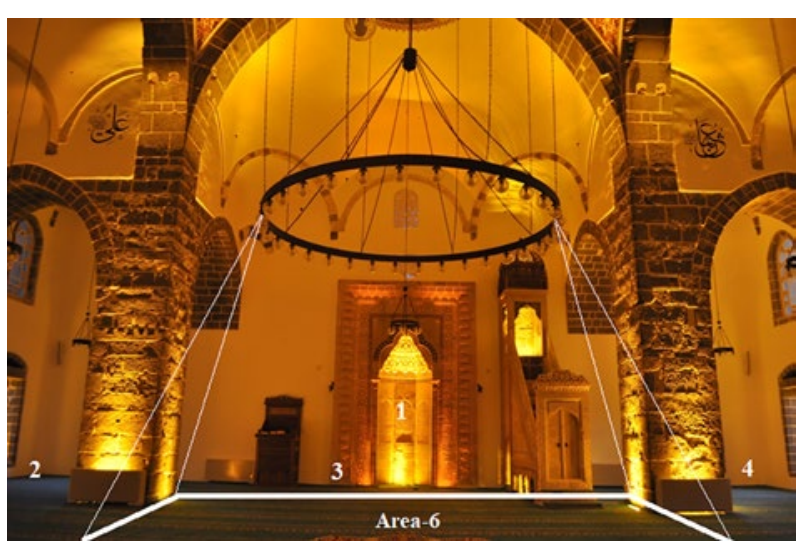

Fig. 5. Lighting scene with only embedded LED wall-washers 
Table 1. The Illuminance Values According to the Places of Worship in Manual Measurements

\begin{tabular}{|c|c|c|c|}
\hline Area & $\begin{array}{c}\text { Daylight } \\
\text { (no artificial } \\
\text { lighting), lx }\end{array}$ & $\begin{array}{c}\text { Daytime } \\
\text { main } \\
\text { lighting, lx }\end{array}$ & $\begin{array}{c}\text { Night } \\
\text { lighting (full } \\
\text { capacity), lx }\end{array}$ \\
\hline 1 & 20 & 75 & 90 \\
\hline 2 & 330 & 330 & 100 \\
\hline 3 & 24 & 80 & 100 \\
\hline 4 & 440 & 440 & 98 \\
\hline 5 & 70 & 90 & 110 \\
\hline 6 & 36 & 200 & 220 \\
\hline 7 & 110 & 124 & 110 \\
\hline 8 & 55 & 64 & 98 \\
\hline 9 & 116 & 130 & 84 \\
\hline 10 & 60 & 72 & 96 \\
\hline
\end{tabular}

in the area-6 measurement at night, 220 lx was measured with the effect of other projectors. Accordingly, $36 \mathrm{~lx}$ value does not comply with CIE criteria in daylight free environment [1, 3, 30], because, at least, $100 \mathrm{~lx}$ illuminance is required for places of worship in the relevant CIE Standard [13]. If 32 halogen lamps are used in area- 6 , it is seen that unnecessary consumption is made if the lamp consumption is considered to be $60 \mathrm{~W}$. If the lighting is realized with LED bulbs, a comparison has been made in the simulation environment for the energy consumption difference. In other words, 32 halogen lamps in area-6 were evaluated as LED lamps in the simulation environment and a comparison was made in terms of their illuminance levels. LED lamps used in the simulation have a power of $9 \mathrm{~W}$. These LED bulbs are in the daylight colour. 9W LED bulb and $60 \mathrm{~W}$ halogen bulb are equivalent. The simulation used is prepared for the purpose of lighting.

It is a non-commercial simulation. The area to be illuminated is divided into equal parts. The calculated section is area- $6(12 \times 12) \mathrm{m}$. The light source is at a height of $5 \mathrm{~m}$. The maintenance factor is accepted as 0.92 . Table 2 was calculated in the simulation environment according to the illuminance level values in the middle point of each region. The average illumination level according to Table 2 is $E_{\text {average }}=$ $118.29 \mathrm{~lx}$. The illuminance level should be $100 \mathrm{~lx}$ or above for places of worship according to CIE Standard. Accordingly, it is understood that the use of a 9W LED lamp is more advantageous than a $60 \mathrm{~W}$ halogen lamp. As a result of the data entered into the simulation, Table 2 shows the illuminnance levels of points in the place of worship.

\section{ECONOMIC EVALUATION IN TERMS OF ENERGY CONSUMPTION}

Daily energy consumption for each illumination device can be calculated as given in equation:

$$
E=P_{b} n_{a} t_{o p}
$$

where $E(\mathrm{~W} \cdot \mathrm{h})$ is the energy, $P_{b}(\mathrm{~W})$ is the power of one bulb, $n_{a}$ is the number of chandelier arms, and $t_{o p}(\mathrm{~h})$ is the operating time of luminaire, which has daily values of 2 hours, 5 hours, and 12 hours

Table 2. Illuminance at the Points in the Place of Worship, $\mathbf{~ x}$ $E_{\min }=18.56 \mathrm{~lx} E_{\max }=399.94 \mathrm{~lx} E_{\text {average }}=118.29 \mathrm{~lx}$

\begin{tabular}{|c|c|c|c|c|c|c|c|c|c|c|}
\hline Meter/Meter & $\mathbf{0 . 7 0 0}$ & $\mathbf{2 . 1 0 0}$ & $\mathbf{3 . 5 0 0}$ & $\mathbf{4 . 9 0 0}$ & $\mathbf{6 . 3 0 0}$ & $\mathbf{7 . 7 0 0}$ & $\mathbf{9 . 1 0 0}$ & $\mathbf{1 0 . 5 0 0}$ & $\mathbf{1 1 . 9 0 0}$ & $\mathbf{1 3 . 3 0 0}$ \\
\hline 0.583 & 15.64 & 14.01 & 9.53 & 13.36 & 13.97 & 13.98 & 13.37 & 9.55 & 14,04 & 15.68 \\
\hline 1.750 & 28.58 & 26.98 & 16.73 & 21.69 & 21.71 & 21.72 & 21.71 & 16.762 & 27.01 & 28.63 \\
\hline 2.917 & 49.13 & 45.99 & 32.44 & 30.56 & 27.27 & 27.27 & 30.57 & 32.47 & 46.02 & 49.18 \\
\hline 4.083 & 87.07 & 68.99 & 62.92 & 41.08 & 37.43 & 37.44 & 41.09 & 62.95 & 69.03 & 87.12 \\
\hline 5.250 & 164.72 & 140.28 & 98.89 & 60.55 & 57.53 & 57.54 & 60.57 & 98.92 & 140.32 & 164.78 \\
\hline 6.417 & 235.46 & 283.84 & 183.06 & 98.47 & 82.22 & 82.22 & 98.49 & 183.09 & 283.88 & 235.52 \\
\hline 7.583 & 359.26 & 406.25 & 262.06 & 144.49 & 111.32 & 111.33 & 144.51 & 262.09 & 406.29 & 359.32 \\
\hline 8.750 & 284.76 & 291.16 & 195.53 & 122.71 & 101.25 & 101.25 & 122.73 & 195.56 & 291.20 & 284.83 \\
\hline 9.917 & 158.65 & 129.60 & 94.322 & 65.659 & 62.80 & 62.81 & 65.67 & 94.35 & 129.64 & 158.71 \\
\hline 11.083 & 77.78 & 58.14 & 47.34 & 36.26 & 37.84 & 37.85 & 36.27 & 47.37 & 58.19 & 77.84 \\
\hline 12.250 & 43.69 & 36.81 & 30.76 & 24.97 & 24.826 & 24.83 & 24.99 & 30.79 & 36.85 & 43.74 \\
\hline 13.417 & 29.25 & 24.81 & 21.80 & 18.71 & 17.335 & 17.34 & 18.72 & 21.82 & 24.84 & 29.30 \\
\hline
\end{tabular}


Table 3. Energy Consumption for Classic Luminaires

\begin{tabular}{|c|c|c|c|}
\hline Equipment & Power per piece, $\mathbf{W}$ & Used pieces & Annual energy consumption, $\mathbf{k W} \cdot \mathbf{h}$ \\
\hline Halogen Lamp & 60 & 64 & 6912 \\
\hline Halogen Projector & 50 & 48 & 8352 \\
\hline Halogen Projector & 100 & 51 & 17244 \\
\hline \multicolumn{3}{|l|}{ TOTAL } & 32508 \\
\hline
\end{tabular}

Table 4. Energy Consumption for LED Luminaires

\begin{tabular}{|c|c|c|c|}
\hline Equipment & Power per piece, $\mathbf{W}$ & Used pieces & $\begin{array}{c}\text { Annual energy consumption, } \\
\mathbf{k W} \cdot \mathbf{h}\end{array}$ \\
\hline LED lamp & 9 & 64 & 725.76 \\
\hline LED wall-washer & 9 & 48 & 1503.36 \\
\hline LED wall-washer & 18 & 51 & 3103.92 \\
\hline \multicolumn{2}{|c|}{ Total } \\
\hline
\end{tabular}

Table 5. Lighting Equipment Costs

\begin{tabular}{|c|c|c|c|c|}
\hline Equipment & Power, $\mathbf{W}$ & Cost, TL/piece & Used pieces & $\begin{array}{c}\text { Total cost for proposed } \\
\text { study, TL }\end{array}$ \\
\hline Halogen lamp & 60 & 9 & 64 & 576 \\
\hline Halogen projector & 50 & 25 & 48 & 1200 \\
\hline Halogen projector & 100 & 40 & 51 & 2040 \\
\hline LED lamp & 9 & 10 & 64 & 640 \\
\hline LED wall-washer & 9 & 150 & 48 & 7200 \\
\hline LED wall-washer & 18 & 250 & 51 & 12750 \\
\hline
\end{tabular}

Table 6. Cost Comparison

\begin{tabular}{|c|c|c|c|c|c|}
\hline $\begin{array}{c}\text { Light source in } \\
\text { fixture }\end{array}$ & $\begin{array}{c}\text { Number of } \\
\text { used elements }\end{array}$ & $\begin{array}{c}\text { Annual energy } \\
\text { consumption, kW·h }\end{array}$ & $\begin{array}{c}\text { Annual energy } \\
\text { cost, TL }\end{array}$ & $\begin{array}{c}\text { Initial investment } \\
\text { cost, TL }\end{array}$ & Total cost, TL \\
\hline Halogen & 163 & 32508 & 27228.7 & 3816 & 31044.7 \\
\hline LED & 163 & 5333.04 & 4466.95 & 20590 & 25056.95 \\
\hline Saving & & 27174.96 & & & 5987.75 \\
\hline
\end{tabular}

according to illuminator location as indoor and outdoor. Annual energy consumption of classical and LED illumination system components was calculated by using equation (1) and summarized in Table 3 and Table 4 respectively. In addition, equipment costs are given in Table 5.

According to the Electricity Market Regulatory Authority of Turkey data, as of 01.01.2020 per unit price of electricity was determined to be 0.8376 $\mathrm{TL} / \mathrm{kW} \cdot \mathrm{h}$ and $27174.96 \mathrm{~kW} \cdot \mathrm{h}$ to be calculated for energy savings. So, annual energy saving is provided to be equal to $27174.96 \mathrm{~kW} \times \mathrm{h} \times 0.8376=$ 22761.7 TL. Difference with LED system will approximately be amortized total cost in about 9 months. It should be noted that lamp lifetimes are not taken into account. It is clear that payback period will further be reduced when considering lifetimes of both lamps. Annual cost comparison by adding initial investment costs is given in Table 6.

\section{CONCLUSION}

This study proposes the illumination of a historical building. An ancient mosque built in the early 16th century selected as a case study. The study includes the physical installation of lighting systems. Within the scope of the study, the installation of LED lighting systems was carried out while preserving the original state of the building. 
In this study, the most important situation is the examination in terms of energy efficiency and saving. Cost calculations have been made for the cases where the lighting is done with classical and LED systems. As a result of the calculations, it has been observed that a great amount of energy can be saved when lighting installations with LED systems are using.

During the day lighting in area-6 with 32 lamps is needed. For the lighting in area- 6 with 32 lamps during the day, 60W halogen lamp lighting application and 9W LED illuminated simulation were compared in terms of energy consumption. The instantaneous total energy consumed by halogen bulbs is $1920 \mathrm{~W}$ and the instantaneous total energy consumed by 32 LED lamps is 288W. Accordingly, it is understandable that when an LED lighting that provides $100 \mathrm{~lx}$ and above are using ambient illumination, recommended by CIE Standard, is achieved with efficiency equal to $85 \%$. The average illuminance level for LED illumination in the simulation environment is equal to $118.29 \mathrm{~lx}$.

\section{ACKNOWLEDGEMENT}

Author would like to thank General Directorate of Foundations of Provincial Directorate of Diyarbakır, Turkey, for their valuable contributions.

\section{REFERENCES}

1. Cengiz. M.S. Simulation and Design Study for Interior Zone Luminance in Tunnel Lighting// Light \& Engineering, 2019, Vol. 27, \#2, pp. 42-51.

2. Iacomussi, Rossi G., Soardo P. Energy Saving and Environmental Compatibility in Road Lighting// Light \& Engineering, 2012, Vol. 20, \#4, pp. 55-63.

3. Cengiz M.S. The Relationship between Maintenance Factor and Lighting Level in Tunnel Lighting//Light \& Engineering, 2019, Vol. 27, \#3, pp. 75-88.

4. Cole M., Driscoll T. The Lighting Revolution: If We Were Experts Before, We're Novices Now// IEEE Transactions on Industry Applications, 2014, Vol. 50, \#2, pp. 1509-1520.

5. Coşkun. T., Gülhan Ö, Şahin C.D., Arsan Z.D., Akkurt G.G. The effect of spatial interventions on historic buildings' indoor climate (Case Study: Tire Necip Paşa Library. Izmir-Turkey)// Energy Procedia, 2017, Vol. 133. pp. 358-366.

6. Kamaruzzaman S. N., Zulkifli N. A Review of the Lighting Performance in Buildings through Energy Effi- ciency// Presented at the 2nd International Conference on Research in Science, Engineering and Technology (ICRSET'2014). March 21-22. 2014. Dubai (UAE).

7. Almodovar-Melendo J. M., Cabeza-Lainez J. M., Rodriguez-Cunill. I. Lighting features in historical buildings: Scientific analysis of the Church of Saint Louis of the Frenchmen in Sevilla// Sustainability, 2018, Vol. 10, \#9, pp. 1-23.

8. Cesario E., Grifoni R.C., Leuzzi A., Paciotti D. Light design in historical buildings: Parameters and prototypes. Comparison of façade behaviour: Metal meshes vs. high-tenacity polymer composite meshes// Presented at International Conference on Environment and Electrical Engineering, 2016, pp. 1-5.

9. Zakaria S. A., Bahauddin A. Light Art for Historical Buildings: A Case Study of the Heritage Buildings in George Town. Penang Island// Procedia - Social and Behavioural Sciences, 2015, Vol. 184, pp. 345-350.

10. Salvadori G., Fantozzi F., Rocca M. \& Leccese. F. The energy audit activity focused on the lighting systems in historical buildings// Energies, 2016, Vol. 9, \#12, pp. 1-13.

11. Górczewska. M.. Some aspects of architectural lighting of historical buildings. WIT Transactions on the Built Environment. 2011. Vol. 121, pp. 107-116.

12. Balocco C., Volante G. A method for sustainable lighting, preventive conservation, energy design and technology-lighting a historical church converted into a university library//Sustainability, 2019, Vol. 11, \#11. pp. 1-17.

13. CIE Standard "Lighting of Work Places - Part 1: Indoor” ISO 8995:2002(E)/ CIE S008/E-2001.

14. Xu X., Collin A., Djokic S.Z., Langella R., Testa A., Drapela J., Experimental evaluation and classification of LED lamps for typical residential applications// Presented at 2017 IEEE PES Innovative Smart Grid Technologies Conference Europe. ISGT-Europe 2017, pp. 1-6.

15. Kim J., Sa G., Kim Y., Baek J. LED-ID application for intelligent lighting// Presented at International Conference on Ubiquitous and Future Networks. ICUFN. 2015-August, pp. 225-227.

16. Matvoz D., Maksić M. Comparison of LED and CFL lamps and their impact on electric power network// Presented at Harmonics and Quality of Power (ICHQP). 2012 IEEE15th International Conference in Hong Kong, 2012, pp. 320-327.

17. Yurci Y., Cengiz Ç., Yapici İ., Cengiz M.S., Yildirim S., Eren M., Palta O., Atiç S. Analysis of Energy Productivity in LED Illumination by Active or Passive Methods// International Conference on Multidiscipli- 
nary Engineering, Science, Education, and Technology, 2017, Baku.

18. Onaygil S., Güler Ö., Erkin E. Cost Analyses of LED Luminaires in Road Lighting// Light \& Engineering, 2019, Vol. 20, \#2, pp. 39-45.

19. Cengiz Ç., Kaynaklı M., Gencer G., Eren M., Yapici İ., Yildirim S., Cengiz M.S. Selection Criteria and Economic Analysis of LEDs// Book of Abstracts. Imeset Int. Conf. Mult. Sci. Eng. Tech., October 27-29, 2017, Bitlis, Turkey.

20. Yurci Y., Yildirim S., Palta O., Cengiz Ç., Atiç S., Yapici I., Cengiz M.S., Eren. M. Numerical Analysis of LED Illumination Productivity Parameter// International Conference on Multidisciplinary, Engineering, Science, Education, and Technology, 2017, (IMESET'17 Baku).

21. Yıldırım S., Yapıcı İ., Atiç S., Eren M., Palta O., Cengiz Ç., Cengiz M.S., Yurci Y. Numerical Analysis of Productivity and Redemption Periods in LED Illimunation// Imeset Book of Abstracts. Int. Conf. Mult. Sci. Eng. Tech., 12-14 July, 2017, Baku.

22. Cengiz M.S., Cengiz Ç. Numerical Analysis of Tunnel LED Lighting Maintenance Factor// IIUM Engineering Journal, 2018, Vol. 19, \#2, pp. 154-163.

23. Çıbuk M., Arı D., Ağgün F. Relay Mechanism with Three way Handshake for Wireless Sensor Networks// Presented at the 8th International Advanced Technologies Symposium, Elazığ, 2017.
24. Çıbuk M., Cengiz M.S. Determination of Energy Consumption According to Wireless Network Topologies in Grid-Free Lighting Systems// Light \& Engineering, 2020, Vol. 28, \#2, pp. 67-76.

25. Cengiz M.S., Cengiz Ç. IOT and Lighting Automation// International Conference on. Imeset Book of Abstracts. Int. Conf. Mult. Sci. Eng. Tech., 12-14 July, 2017, Baku.

26. Arı D., Çıbuk M., Ağgün F. Effect of Relay Priority Mechanism on Multi Hop Wireless Sensor Networks// Bitlis Eren University Journal of Science and Technology, 2017, Vol. 7, \#2. pp. 145-153.

27. Dos Santos Oliveira G., De Oliveira E.P., Da Silva A.P., De Moura Carvalho C.C.M. Power quality of LED lamps// Presented at International Conference on Harmonics and Quality of Power, ICHQP, 2016-December, pp. 575-580.

28. Varhan D. LED Lighting in Historical Spaces and Applications// Master Thesis. Bitlis Eren University. Turkey. October 2019.

29. Tuncer O.C. Diyarbakır Mosques. Diyarbakır Metropolitan Municipality// Culture and Art Publications, Diyarbakır, 1996.

30. Onaygil S. Turkish Electrical Distribution Company Illumination Training Seminar, 23-24 January, 2007, Ankara, Turkey.

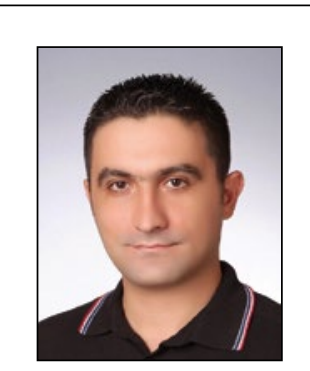

\section{Serhat Berat Efe}

received his Ph. D. degree from Frrat University, Turkey, in 2014. His main research areas are power system analysis, power quality and renewable energy sources. He is currently working at Bandırma Onyedi Eylül University as Assistant Professor with the Electrical Engineering department

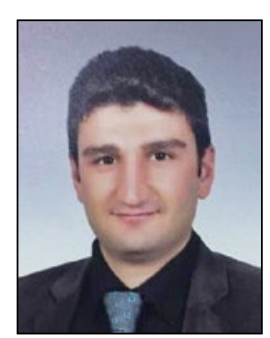

\section{Derman Varhan}

received his M. Sc. degree in the field of Electrical and Electronics Engineering from Bitlis Eren University, Turkey, in 2019. He is currently working at General Directorate of Foundations, provincial directorate of Diyarbakır, Turkey, as electrical and electronics engineer 